\title{
Gergin Omurilik (Tethered Cord) Sendromlu Hastalarda Intraoperatif Nörofizyolojik Monitörizasyon: 30 Olguluk Klinik Deneyim
}

\author{
Adem Yılmaz ${ }^{1}$, Burak Özdemir ${ }^{1}$, Kadir Altaş ${ }^{1}$, Muyassar Mirkhasilovaa ${ }^{1}$, Mustafa Kılıç${ }^{1}$, Ahmet Murat Müslüman ${ }^{1}$
}

ÖZET:

Gergin omurilik (tethered cord) sendromlu hastalarda intraoperatif nörofizyolojik monitörizasyon: 30 olguluk klinik deneyim

Amaç: Gergin omurilik sendromu, konus medullarisin normal seviyesinden daha aşağıda sonlanması veya konus medullarisin fizyolojik olarak normal seviyesine gelmesine engel olan lezyonların genel adıdır. Mikronöroşirürjikal müdahale ile gergin olan konus serbestleştirilir. Bu cerrahi sırasında, anestezi sonlandırıldığında ya da postoperatif takiplerde geçici veya kalıcı nörolojik defisitler oluşabilmektedir. İntraoperatif nörofizyolojik monitörizasyon (IONM) kullanımı bu riski azaltmaktadır. Bu çalışmamızda kliniğimizde opere edilen olgular üzerinden intraoperatif nörofizyolojik monitörizasyon kullanımının önemini ve klinik sonuçlarımızı bildirmeyi amaçladık.

Yöntem ve Gereçler: 2015-2016 yılları arasında kliniğimizde ameliyat edilen 30 olgunun iONM bulguları, preoperatif ve postoperatif nörolojik bulguları değerlendirilerek sonuçlar bildirildi. Gergin omurilik ameliyatlarının hepsinde intraoperatif nörofizyolojik monitörizasyon (iONM) kullanıldı. Somatosensoriyal potansiyeller (SEP), motor uyarılmış potansiyeller (MEP), free-run EMG yanıtları, eksternal sfinkter kası MEP ve prob ile direkt uyarılan sinir dokusu potansiyelleri kaydedildi.

Bulgular: Vakaların 20'si erkek, 10'u kadın hasta, yaş ortalaması 9.03 idi. Olgulardan sadece 1'inde SEP değerlerinde artış gözlendi. Olgulardan 3 tanesinde ek nörolojik hasar gelişti. Bunlardan 1 tanesi 48 saat süreyle geçici seyretti, diğer iki olguda ise kalıcı nörolojik hasarlar gözlendi.

Sonuç: Gergin omurilik sendromu ameliyatlarında, çalışmamızda ve literatürde de gösterildiği üzere deneyimli bir ekip ve uygun monitörizasyon ile nörolojik hasar görülme intimali azalabileceğinden, tüm modaliteleri ile iONM kullanımı önerilir.

Anahtar kelimeler: Gergin omurilik sendromu, intraoperatif nöromonitörizasyon, nörofizyoloji, untethering

\section{ABSTRACT:}

Intraoperative neurophysiological monitoring in tethered cord syndrome: clinical experience with 30 cases

Objective: The tethered cord syndrome (TCS) refers to lesions that can cause the conus medullaris to be low-lying or incapable of movement within the spinal canal. Tight conus medullaris is untethered by microneurosurgical operation. Patients may have additional persistent or transient neurological deficits in postoperative follows. The use of intraoperative neurophysiological monitoring (IONM) reduces risks of being neurological deficits. In our article, we aimed to show the importance of using intraoperative neurophysiological monitoring with results of cases operated in our department.

Material and Methods: The results of IONM findings, preoperative and postoperative neurological findings of 30 patients who were operated in our clinic between 2015-2016 were reported. Intraoperative neurophysiological monitoring (IONM) was used in all cases with tethered cord sydrome. Somatosensory evoked potential (SEP), motor evoked potential (MEP), free-run EMG responses, external sphincter muscle MEP and direct monopolar probe-evoked potentials were recorded.

Results: There were 20 male and 10 female patients with a mean age of 9.03 in our study. There was an increase in SEP values in only one of the cases. Additional neurological deficit arised in three cases; 1 transient ( 48 hours) and 2 persistent.

Conclusion: As our and other studies in literature has shown that using appropriate monitorization with experienced team decreases the risk of developing neurological injury; IONM should be used with its all modalities.

Keywords: Tethered cord syndrome, intraoperative neurophysiological monitoring, neurophysiology, untethering

Ş.E.E.A.H. Tıp Bülteni 2017;51(1):43-7
I'stanbul Sişli Hamidiye Etfal Eğitim Araştırma Hastanesi, Beyin ve Sinir Cerrahisi Servisi, İstanbul - Türkiye

Yazışma Adresi / Address reprint requests to: Adem Yılmaz,

İstanbul Şişli Hamidiye Etfal Eğitim Araştırma Hastanesi, Beyin ve Sinir Cerrahisi Servisi, istanbul - Türkiye

E-mail / E-posta: ademyilmaz70@yahoo.com

Telefon / Phone: +90-212-373-5000

Geliş tarihi / Date of receipt: 26 Ocak 2017 / January 26, 2017

Kabul tarihi / Date of acceptance: 27 Şubat 2017 / February 27, 2017 


\section{Gíriş}

Gergin omurilik sendromu spinal kordun anormal bir nedenden dolayı gerilmesi olup, 1000 doğumda 0.05-0.25 insidansı olmasından dolayı nadir bir durumdur (1-3). Omuriliğin gerginliği düşük konus medullaris ve yapışık bir filum terminale nedeni ile olabilir. Diğer yandan omuriliğin normal fizyolojik seviyesine gelmesini engelleyen kemik spur, fibröz bant veya doğumda geçirilmiş operasyonlara sekonder yapışıklıklar da gergin omurilik sendromuna neden olabilir (4). Untethering işlemi de gerginliğe neden olan lezyona yönelik yapılmalıdır. Filum terminale bazı olgularda normal sinir demetleri ile karışabilmekte ve deneyim ve tecrübe ayırt etmek için bazen yeterli olmayabilir. Bundan dolayı intraoperatif nörofizyolojik monitö- rizasyon (IONM), gergin omurilik sendromlu vakalarda tavsiye edilmektedir. Normal sinir dokusunu ayırt etmede yardımcı olmaktadır. Makalemizde de IONM kullanılarak opere edilen gergin omurilik sendromlu vakaların preoperatif ve postoperatif dönemdeki klinik ve nörofizyolojik sonuçlarını literatür eşliğinde değerlendirdik.

\section{GEREÇ VE YÖNTEM}

2015 Ocak- 2016 Aralık tarihleri arasında gergin omurilik sendromu nedeni ile başvuran 30 hastaya omurilik serbestleştirme operasyonu yapıldı. Kemik spur veya fibröz bant nedeni ile split korda sahip olan 10 hastaya (Tablo-1), ek olarak lezyonun eksizyonu da aynı seansta yapıldı. Hepsinde cerrahi işlem boyunca IONM modalitelerinden, motor uya-

\begin{tabular}{|c|c|c|c|c|c|c|}
\hline Hasta no & Cinsiyet & Yaş & Operasyon sonucu & $\begin{array}{l}\text { Postoperatif ek } \\
\text { nörolojik bulgu }\end{array}$ & iONM* bulguları & Sonuç \\
\hline 1 & $E$ & 30 & FTS* & PP: $3 / 5$ & - & $\begin{array}{l}48 \text { saat sonra } \\
\text { normal }\end{array}$ \\
\hline 2 & $E$ & 13 & $\mathrm{FBE}^{*}+\mathrm{FTS}$ & - & - & - \\
\hline 3 & $E$ & 10 & FTS & - & - & - \\
\hline 4 & K & 10 & $\mathrm{KSR}^{*}+\mathrm{FTS}$ & - & - & - \\
\hline 5 & K & 4 & FTS & - & - & - \\
\hline 6 & $E$ & 2 & FTS & - & SEP* artışı & - \\
\hline 7 & $E$ & 7 & FTS & - & - & - \\
\hline 8 & $E$ & 4 & $\mathrm{KSR}+\mathrm{FTS}$ & - & - & - \\
\hline 9 & $\mathrm{~K}$ & 11 & $\mathrm{FBE}+\mathrm{FTS}$ & - & - & - \\
\hline 10 & $\mathrm{~K}$ & 14 & $\mathrm{KSR}+\mathrm{FTS}$ & SaDF*: $3 / 5$ & - & Kalıcı defisit \\
\hline 11 & $\mathrm{~K}$ & 2 & FTS & - & - & - \\
\hline 12 & $E$ & 3 & FTS & - & - & - \\
\hline 13 & $\mathrm{~K}$ & 5 & FTS & - & - & - \\
\hline 14 & $E$ & 36 & FTS & - & - & - \\
\hline 15 & $E$ & 9 & FTS & - & - & - \\
\hline 16 & $E$ & 3 & FTS & - & - & - \\
\hline 17 & $E$ & 5 & $\mathrm{KSR}+\mathrm{FTS}$ & - & Geçici MEP* azalması & - \\
\hline 18 & $\mathrm{~K}$ & 3 & FTS & - & - & - \\
\hline 19 & $E$ & 2 & FTS & - & - & - \\
\hline 20 & $\mathrm{~K}$ & 17 & FTS & - & - & - \\
\hline 21 & $E$ & 7 aylık & $\mathrm{FBE}+\mathrm{FTS}$ & - & - & - \\
\hline 22 & $\mathrm{~K}$ & 5 & $\mathrm{KSR}+\mathrm{FTS}$ & - & - & - \\
\hline 23 & $E$ & 1 & FTS & - & - & - \\
\hline 24 & $E$ & 20 & FTS & - & - & - \\
\hline 25 & $E$ & 17 & FTS & SoDF* ve SoDiE* $3 / 5$ & MEP azalması & Kalıcı defisit \\
\hline 26 & $E$ & 10 & FTS & - & - & - \\
\hline 27 & $E$ & 4 & FTS & - & - & - \\
\hline 28 & $\mathrm{~K}$ & 7 & $\mathrm{KSR}+\mathrm{FTS}$ & - & - & - \\
\hline 29 & $E$ & 2 & FTS & - & - & - \\
\hline 30 & $E$ & 14 & $\mathrm{KSR}+\mathrm{FTS}$ & - & - & - \\
\hline
\end{tabular}

*:IONM: Intraoperatif nöromonitörizasyon, FTS: Filum terminale serbestleştirilmesi, KSR: Kemik spur rezeksiyonu, FBE: Fibröz bant eksizyonu, PP: Paraparezi,

SaDF: Sağ Ayak Dorsifleksiyonu SoDF: Sol Ayak Dorsifleksiyonu, SoDiE: Sol diz eklemi ekstansiyonu, SEP: Somatosensoriyal uyarılmış Potansiyel, MEP: Motor uyarılmış potansiyeller. 
rılmış (evoked) potansiyeller (MEP), somatosensoriyal uyarılmış (evoked) potansiyeller (SEP), free-run (sürekli) EMG potansiyelleri, eksternal sfinkter kası MEP potansiyelleri ve prob ile direkt sinir dokusuna dokunularak elde edilmiş potansiyeller kullanıldı. Ameliyat salonunda, anestezi ekibinin entübasyon işleminin hemen ardından potansiyel kayıtları için elektrotlar hastanın ilgili kas bölgelerine takıldı. Aynı zamanda anestezi işleminin başından sonlandırılmasına kadar ameliyat boyunca free-run EMG ile de kayıtlar gerçekleştirildi. Cerrahi işlem sırasında monopolar prob ile de fonksiyonel sinir dokusu ile filum terminale ayrımı için direkt cerrahi alandaki dokuya dokunularak elde edilen uyarı potansiyelleri kaydedildi. Filum terminale serbestleştirmesi sırasında bütün olgularda monopolar prob bu şekil-

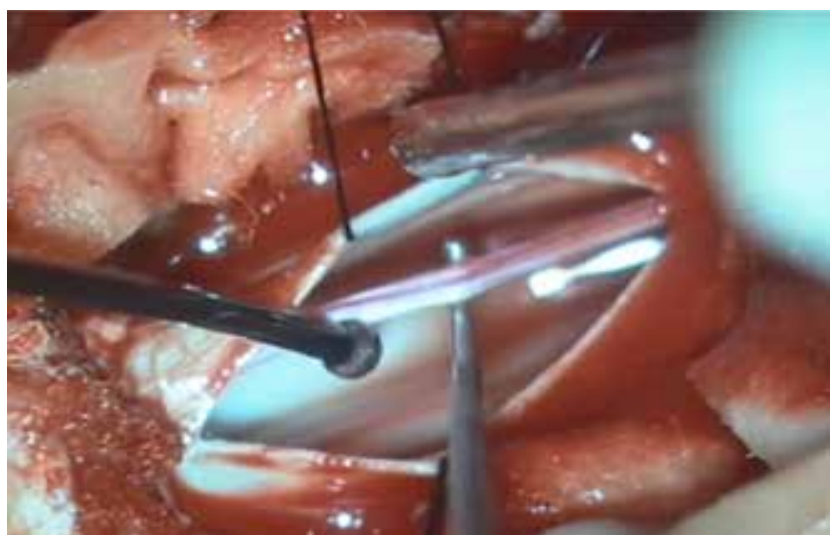

Resim-1: Gergin omurilik sendromlu olguda filum terminale eksizyonu öncesi monopolar prob ile direkt sinir uyarımı de sinir dokusunu anlamada kullanıldı (Resim-1). Operasyonlar boyunca MEP, SEP, free -run EMG ve sfinkter MEP kayıtları nörofizyoloji ekibi tarafından değerlendirildi ve cerraha istediği zaman bilgi verildi. Çalışmamızda preoperatif ve postoperatif nörolojik bulgular ile intraoperatif nörofizyolojik bulgular değerlendirilerek sonuçlar elde edildi.

\section{BULGULAR}

Vakaların 20'si erkek, 10'u kadın hasta idi (Tablo-1). Yaşortalaması 9.03 (minumum 7 ay-maksimum 36 yaş) bulundu (Tablo-1). Hastalardan 20`sinde kalın gergin filum terminale ve düşük konus medullaris vardı (Tablo-1) (Resim-2). Diğer 10 hastada ek olarak split korda neden olan kemik spur veya fib-

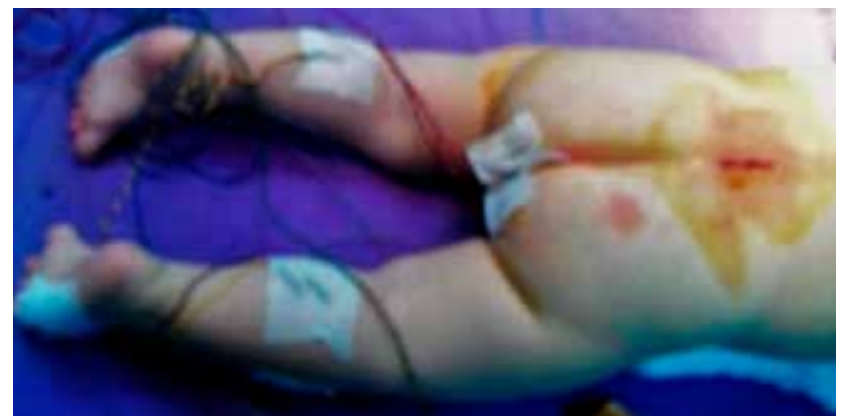

Resim-3: Gergin omurilik sendromlu 1 yaşındaki olguda MEP, SEP ve sfinkter MEP kayıtları için tibialis posterior ve anterior, hallucis ve eksternal sifinkter bölgelerine bağlanmış elektrotların görünümü ve ameliyat için kullanılacak olan insizyon hattı.

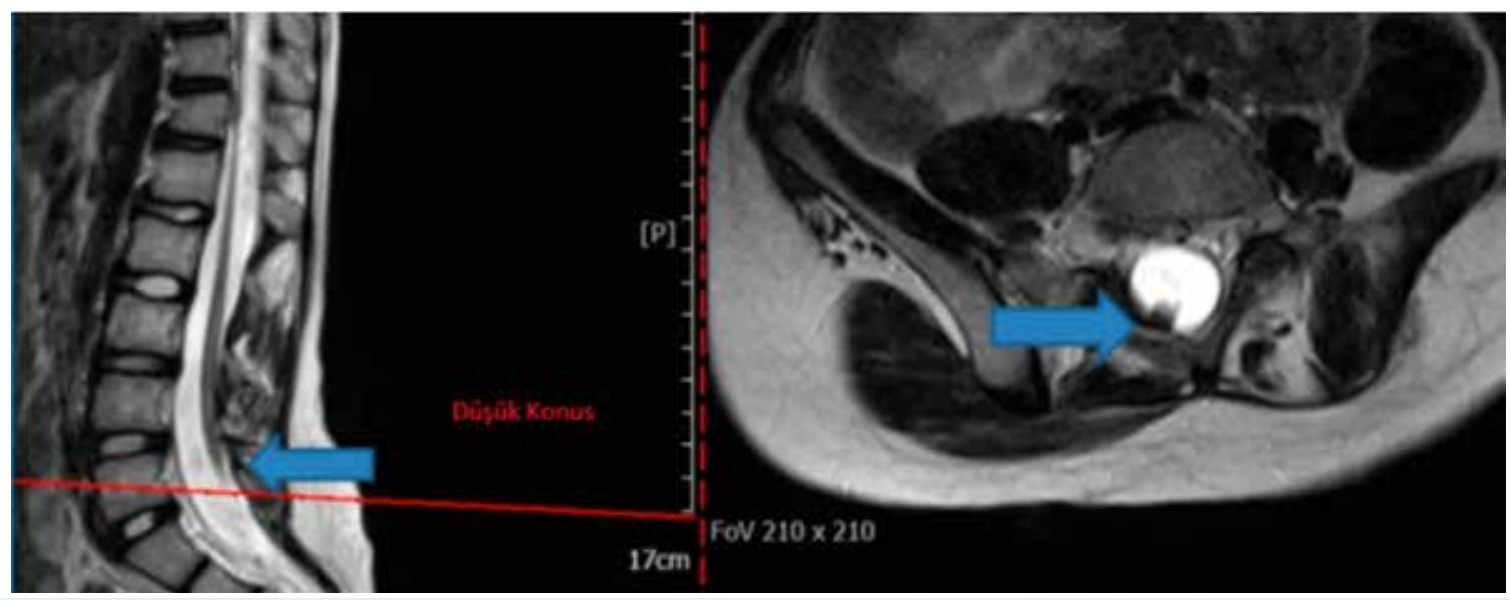

Resim-2: Olgularımızdan birinin preoperatif dönemde T2 sekanslı aksiyal ve sagittal MRI görüntüsünde; L5 seviyesinde low - conus (düşük konus medullaris) ve kalın gergin filum terminale görünümünü görmekteyiz. 
röz bant da bulunuyordu (Tablo-1). 10 hasta daha önceden spina bifida nedeni ile opere olmuş ve takiplerde gergin omurilik sendromu teşhisi konulmuş hastalardı. 20 hastada daha önceden herhangi bir spinal cerrahi öyküsü yoktu. Operasyonlar boyunca kullanılan IONM sonuçları değerlendirildiğinde; olguların hiçbirinde bazal SEP değerlerine göre, işlem sonundaki SEP değerlerinde azalma görülmedi. 1 olguda SEP değerlerinde bazal değerlere göre artma gözlendi (6 numaralı olgu, Tablo- 1 ). 2 olguda ameliyat sırasında MEP değerlerinde bazal değerlere göre azalma gözlendi, 1 olguda geçici olup ameliyat sonunda bazal MEP değerine ulaştığı görüldü. (17,25 numaralı olgular, Tablo-1). Olguların 3'ünde postoperatif dönemde ek nörolojik defisitler gözlendi. Bunlardan 1 olguda oluşan nörolojik defisit 48 saat sonra iyileşerek geçici seyretti (1 numaralı olgu, Tablo-1). Diğer iki olguda ise kalıcı bir nörolojik tablo olarak seyretti. (10,25 numaralı olgular, Tablo-1). Kalıcı nörolojik defisite sahip olan iki olgudan 1'inde IONM da MEP değerlerinde kalıcı bir azalma görüldü (25 numaralı olgu, Tablo-1). Diğer olgularda ise MEP değerleri bazal değerlerle aynı kaldı. Bu olgular dışında diğer olgularda iONM sırasında potansiyellerde değişiklik gözlenmedi.

\section{TARTIŞMA}

Cerrahi işlemlerde sinir dokusunu korumak için geliştirilen birçok yöntemden biri olan IONM son 20 yıldır yaygın olarak kullanılmaya başlandı. IONM da temel olarak SEP ve MEP potansiyelleri kaydedilse de sfinkter MEP, free-run EMG, bulbokavernöz potansiyeller de kayıt edilmesi önerilmektedir (5). Bizim çalışmamızda bütün olgularda MEP, SEP, free-run EMG ve prob ile direkt sinir dokusu uyarım potansiyelleri kayıtlarda kullanıldı. SEP, periferik sinirler ve dermatom sinirleri uyarılarak elde edilen potansiyellerdir (6). Üst ekstremite monitörlenmesi için median sinir ve ulnar sinir traselerine elektrotları takılır, alt ekstremitede tibialis posterior ve peroneal bölgeye takılır. MEP ise, motor yolların fonksiyonunu ölçen potansiyellerdir. Yapısal ve fonksiyonel bütünlügü korumada etkili bir yöntemdir. Cerraha hızlı yanıt verme imkânı sağla- dığından tercih edilmesi gerekir $(1,6)$. Üst ekstremite kayıtları için abductor policis brevis, alt ekstremite kayıtları için tibialis anterior ve abductor hallucis, sfinkter tonusu için de eksternal sfinkter kasına elektrot takılmalıdır (5) (Resim-3). Bizim çalışmamızda da bütün olgularda tibialis anterior ve posterior, abductor hallucis ve eksternal sfinkter kaslarına elektrotlar takılarak kayıtlar elde edildi.

Gergin omurilik sendromu cerrahisinde postoperatif dönemde kalıcı nörolojik defisit gelişme olasılığı \%5 olmasına rağmen (7), geçici defisitler de eklenirse bu oran \%10'lara çıkmaktadır $(4,8)$. Çalışmamızda bu oranlardan kalıcı defisit oranına bakacak olursak, iki olguda kalıcı nörolojik hasar saptandı ve çalışmamızda görülme oranı \%6.6 bulundu.

Literatüre bakıldığında, Paradiso ve ark. (9) yaptığı 44 vakalık çalışmada, olgulardaki postoperatif nörolojik defisit ve intraoperatif nörofizyolojik değişiklikler değerlendirilmiş ve SEP değerlerinin yüksek sensitivite ve spesifiteye sahip olduğunu bulmuştur. Bizim çalışmamızda postoperatif ek defisiti olan olgularda SEP değerlerinde bazal değerlere göre, herhangi bir değişiklik gözlenmedi.

MEP potansiyelleri çalışmamızda değerlendirildiğinde, 3 olguda postoperatif dönemde ek defisit olmasına rağmen, bunlardan sadece 1 olguda MEP değerlerinde kalıcı azalma saptandı. Bu da iONM işleminde yalancı negatif sonucun görülebileceğini akla getirmiştir (10). Diğer yandan literatüre bakıldığında IONM işleminde MEP ve SEP kayıtları birlikte değerlendirildiğinde işlemin özgünlüğü \%92, hassasiyeti ise \%99 oranında olmaktadır (11). Nörolojik hasar olmasına rağmen IONM değerlerinde herhangi bir değişimin olmamasının, yani yalancı negatif sonucun nedeni literatüre bakıldığında, ameliyat sırasında kullanılan bipolar koterin potansiyel kayıtlarını etkilemesi veya anestezi ajanlarının etkisi ve kas gevşeticilerin derinleştirilmesi olabileceği düşünüldü $(10,12)$.

Beyazova ve ark. (1) yaptığı bir çalışmada, gergin omurilik sendromlu 10 olgu IONM kullanılarak opere edilmiş ve sonuçlara göre MEP ve SEP değerlerinde bir değişiklik saptanmamış. Prob ile direkt sinir dokusuna dokunularak elde edilen uyarının, normal sinir dokusunu cerrahi işlem sırasında tanımada ve korumada etkin olduğunu vurgulamış. 
Bizim çalışmamızda, bütün olgularda filum terminale eksizyonu hemen öncesinde muhtemel filum terminale üzerine monopolar prob ile dokunularak uyarı verildi ve direkt sinir uyarımı yapıldı ve sinir dokusu yanıtı alınmıyor ise eksizyon yapıldı (Resim-1). Filum terminale eksizyonu anında alınan bazal potansiyel değerler, eksizyon sonrasında da değişmedi.

Kothbauer ve ark. (13) yayınladığı başka bir çalışmada MEP değerlerinin cerraha anlık bilgi vermede etkin olduğuna, özellikle de direkt prob ile sinir uyarımı potansiyellerinin operasyonu kolaylaştırdığına dikkat çekilmiştir.

Mevcut değerler ve bulgular incelendiğinde çalışmamızda literatüre yakın sonuçlar elde edilmekle birlikte, IONM da özellikle prob ile direkt sinir dokusu uyarımı potansiyelleri nörolojik fonksi-

\section{KAYNAKLAR}

1. Beyazova $M$, Zinnuroglu M, Emmez $H$, Kaya $K$, Ozkose $H Z$, Baykaner MK, et al. Intraoperative Neurophysiological Monitoring During Surgery for Tethered Cord Syndrome.Turk Neurosurg 2010; 20: 480-4. [CrossRef]

2. Kanev PM, Nierbrauer KS. Reflections on the natural history of lipomyelomeningocele. Pediatr Neurosurg 1995; 22: 137-140. [CrossRef]

3. Soonawala N, Overweg-Plandsoen WC, Brouwer OF. Early clinical signs and symptoms in occult spinal dysraphism: A retrospective case study of 47 patients. Clin Neurol Neurosurg 1999; 101: 11-4. [CrossRef]

4. Choux M, Lena G, Genitori L, Foroutan M. The surgery of occult spinal dysraphism. Adv Tech Stand Neurosurg 1994; 21: 183238. [CrossRef]

5. Gonzalez $A A 1$, Jeyanandarajan $D$, Hansen $C$, Zada $G$, Hsieh $P C$. Intraoperative neurophysiological monitoring during spine surgery: a review. Neurosurg Focus 2009; 27: E6. [CrossRef]

6. Aydınlar E. Intraoperatif omurilik monitörlenmesi. Zileli M, Özer $F$ (eds). Omurga ve Omurilik Cerrahisi. Cilt 1. Izmir : Intertıp Yayınevi; 2014. p.413-9.

7. Pang D, Wilberger JE. Tethered cord syndrome in adults. J Neurosurg 1982; 57: 32-47. [CrossRef] yonu korumada ameliyatı yapan hekime yardımcı olmaktadır.

\section{SONUÇ}

IONM işlemi, yeterli ekipman, tecrübeli ve deneyimli bir cerrah, deneyimli bir anestezist ve iyi bir nörofizyoloji uzmanı ile gergin omurilik sendromu olgularında güvenli bir cerrahi işlem planlamamıza olanak sağlar. IONM işleminde SEP ve MEP değerlerinin birlikte değerlendirilmesi işlemin hassasiyetini ve özgünlüğünü arttırmaktadır. Cerrahi işlem sırasında nörolojik hasarın gözlenme ihtimalini en aza indirgemek için, aynı zamanda sfinkter MEP, free-run EMG değerlerinin ve prob ile direkt sinir dokusu uyarılarak elde edilen potansiyel değerlerin kullanılmaları önerilir.

8. Pierre-Kahn A, Zerah $M$, Renier D, Cinalli G, Sainte-Rose $C$, Lellouch-Tubiana $A$, et al. Congenital lumbosacral lipomas. Childs Nerv Syst 1997; 13: 298-335. [CrossRef]

9. Paradiso $G$, Lee GY, Sarjeant $R$, Hoang $L$, Massicotte EM, Fehlings MG. Multimodality intraoperative neurophysiologic monitoring findings during surgery for adult tethered cord syndrome: analysis of a series of 44 patients with long-term follow-up. Spine (Phila Pa 1976) 2006; 31: 2095-102. [CrossRef]

10. Nuwer MR, Dawson EG, Carlson LG, Kanim LEA, Sherman JE. Somatosensory evoked potential spinal cord monitoring reduces neurologic deficits after Scoliosis surgery: Results of a large multicenter survey. Electroencephalography and Clinical Neurophysiology 1995; 96: 6-11. [CrossRef]

11. Sutter M, Deletis V, Dvorak J, Eggspuehler A, Grob D, MacDonald D, Mueller A, Sala F, Tamaki T. Current opinions and recommendations on multimodal intraoperative monitoring during spine surgeries. Eur Spine J 2007; 16: 232-237. [CrossRef]

12. Wang $A C$, Than $K D$, Etame $A B$, La MF, Park P. Impact of anesthesia on transcranial electric motor evoked potential monitoring during spine surgery: a review of the literature. Neurosurg Focus 2009; 27: E7. [CrossRef]

13. Kothbauer KF, Novak K. Intraoperative monitoring for tethered cord surgery: an update. Neurosurgn Focus 2004; 16: E8. [CrossRef] 